\title{
Advanced Transmission Electron Microscopy of Pu Alloys
}

A.J. Schwartz, M.A. Wall, W.G. Wolfer, K.T. Moore

This article was submitted to Plutonium Futures - The Science 2003, Albuquerque, New Mexico July $6-10,2003$

\section{January 27, 2003}

U.S. Department of Energy

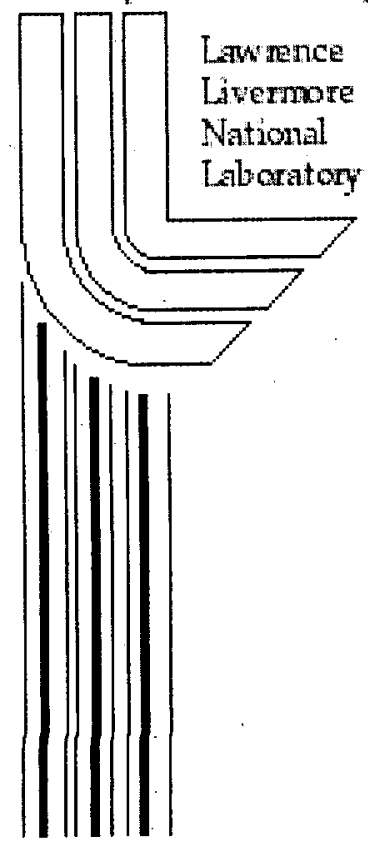

Approved for public release; further dissemination unlimited 


\section{DISCLAIMER}

This document was prepared as an account of work sponsored by an agency of the United States Government. Neither the United States Government nor the University of California nor any of their employees, makes any warranty, express or implied, or assumes any legal liability or responsibility for the accuracy, completeness, or usefulness of any information, apparatus, product, or process disclosed, or represents that its use would not infringe privately owned rights. Reference herein to any specific commercial product, process, or service by trade name, trademark, manufacturer, or otherwise, does not necessarily constitute or imply its endorsement, recommendation, or favoring by the United States Government or the University of California. The views and opinions of authors expressed herein do not necessarily state or reflect those of the United States Government or the University of California, and shall not be used for advertising or product endorsement purposes.

This is a preprint of a paper intended for publication in a journal or proceedings. Since changes may be made before publication, this preprint is made available with the understanding that it will not be cited or reproduced without the permission of the author.

This report has been reproduced directly from the best available copy.

Available electrónically at http://www.doc.gov/bridge

Available for a processing fee to U.S. Department of Energy

And its contractors in paper from

U.S. Department of Energy

Office of Scientific and Technical Information

P.O. Box 62

Oak Ridge, TN 37831-0062

Telephone: (865) 576-8401

Facsimile: (865) 576-5728

'E-mail: reports@adonis.osti.gov

Available for the sale to the public from

U.S. Department of Commerce

National Technical Information Service

5285 Port Royal Road

Springfield, VA 22161

Telephone: (800) 553-6847

Facsimile: (703) 605-6900

E-mail: orders@ntis.fedworld.gov

Online ordering: http://www.ntis.gov/ordering.htm

OR

Lawrence Livermore National Laboratory

Technical Information Department's Digital Library

http://www.llnl.gov/tid/Library.html 


\title{
Advanced Transmission Electron Microscopy of Pu Alloys
}

\author{
Adam J. Schwartz, Mark A. Wall, Wilhelm G. Wolfer, and Kevin T. Moore \\ Chemistry \& Materials Science Directorate \\ Lawrence Livermore National Laboratory \\ L-355 \\ 7000 East Avenue \\ Livermore, CA 94550
}

\section{Introduction}

The characterization of microstructural changes in Pu-Ga alloys resulting from storage and aging phenomena is an important technical challenge to the nuclear Stockpile Stewardship program. We have identified at least two age-related phenomena that may occur in Pu alloys, dimensional changes due to the initial transient, helium accumulation, and void swelling, and phase instability. The initial transient is a well-known effect that results from the initial cascade damage. This form of dimensional change tends to saturate within approximately two years. A second contributor to dimensional change is the build-up of helium as a result of the alpha decay. Helium is generated at a rate of approximately 40 parts per million per year. Positron annihilation results by Howell ${ }^{1}$ indicate that the helium atoms will quickly fill a nearby vacancy and diffuse through the lattice as a helium filled vacancy. Void swelling is potentially the most severe mechanism of dimensional change in Pu alloys. It has been observed in all materials exposed to irradiation, but has yet to be seen in naturally aged $\mathrm{Pu}$.

Phase instability is a potential concern due to the fact that the $\delta$-phase is thermodynamically metastable at room temperature. Timofeeva ${ }^{2}$ has shown that the $\delta$-phase will decompose to $\delta$ phase and $\mathrm{Pu}_{3} \mathrm{Ga}$ given enough time at ambient temperature. At sub-ambient temperatures, the $\delta$-phase undergoes a displacive or martensitic phase transformation to the monoclinic $\alpha$ '-phase, which is approximately $20 \%$ more dense. Phase transformations such as these would result in density changes, dimensional changes, and changes in mechanical properties.

Traditional characterization techniques such as optical microscopy, $\mathrm{x}$-ray diffraction and scanning electron microscopy are insensitive to many of the age-related microstructural changes. In this investigation, we have applied advanced transmission electron microscopy (TEM) to investigate the microstructure and bonding of Pu alloys. A $300 \mathrm{keV}$ Phillips CM300FEG with a field emission gun electron source and Gatan Imaging Filter are used for the investigations. 


\section{Results}

Advanced TEM has been used to characterize the helium bubble distribution in new and old $\mathrm{Pu}$ alloys. Figure la shows a TEM micrograph of He bubbles in a 42-year old material. These results have been coupled to rate equation modeling to predict the evolution of He bubble number density and average size with size as shown in Figure $1 \mathrm{~b}$.
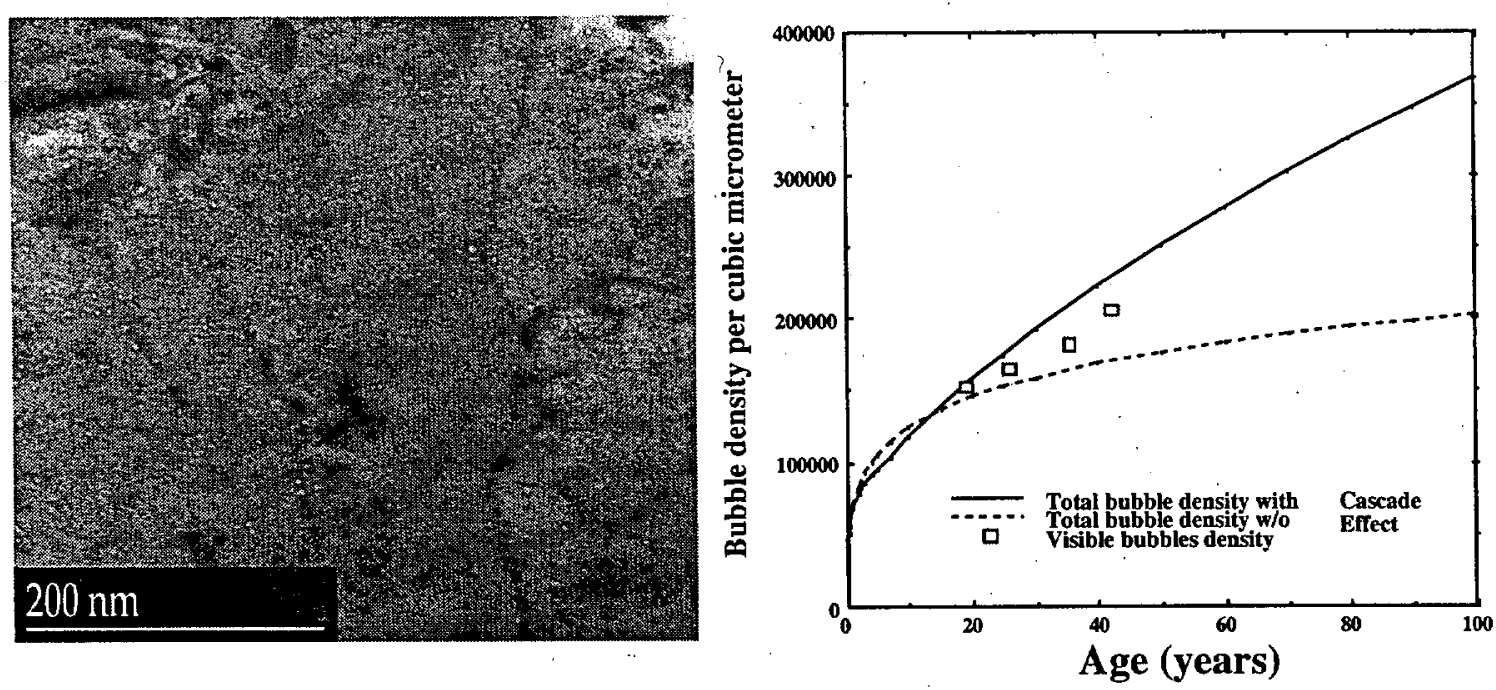

Figure 1. (a) Bright field TEM micrograph of the 42-year old material. The image is taken in the under focus condition such that the bubbles appear as dark rings surrounding bright dots. (b) Model prediction of the bubble number density as a function of age.

The structure and composition of a naturally occurring $\mathrm{Pu}-\mathrm{Fe}$ intermetallic phase has been determined by combining high energy TEM with simulated and experimental electron diffraction simulation and energy dispersive spectroscopy. A phase belonging to the space group $14 / \mathrm{mcm}$ has been identified in a Pu-Ga alloy containing trace amounts of $\mathrm{Fe}$ and $\mathrm{Ni}$ using electron diffraction and energy-dispersive X-ray spectroscopy (EDXS) in a transmission electron microscope. The plane group symmetry of six experimental diffraction patterns shows that the structure of this phase was at least body-centered orthorhombic. Simulated diffraction patterns, generated from the body-centered tetragonal structure of $\zeta \mathrm{Pu}_{6} \mathrm{Fe}$ with the space group $I 4 / \mathrm{mcm}$, match the experimental diffraction patterns closely. These results present the first crystallographic evidence for the existence of $\zeta \mathrm{Pu}_{6} \mathrm{Fe}$ in a $\mathrm{Pu}-\mathrm{Ga}$ alloy. Figure $2 \mathrm{a}$ is a TEM micrograph of the $\mathrm{Fe}$-containing phase in the $\delta$-Pu lattice. Figure $2 \mathrm{~b}$ is an energy dispersive spectrum showing high levels of Fe. The Pu/Fe ratio of the phase yielded by EDXS was $12.5 \%$ and the $\mathrm{Pu} /(\mathrm{Fe}+\mathrm{Ni})$ ratio was $15.9 \%$. These results suggest that $\mathrm{Ni}$ substitutes for $\mathrm{Fe}$ in the $\zeta$ 
$\mathrm{Pu}_{6} \mathrm{Fe}$ lattice. By coupling electron diffraction, simulation and $\mathrm{EDS}$, we are able to determine that this is the body centered tetragonal phase $\zeta-\mathrm{Pu}_{6} \mathrm{Fe}$.
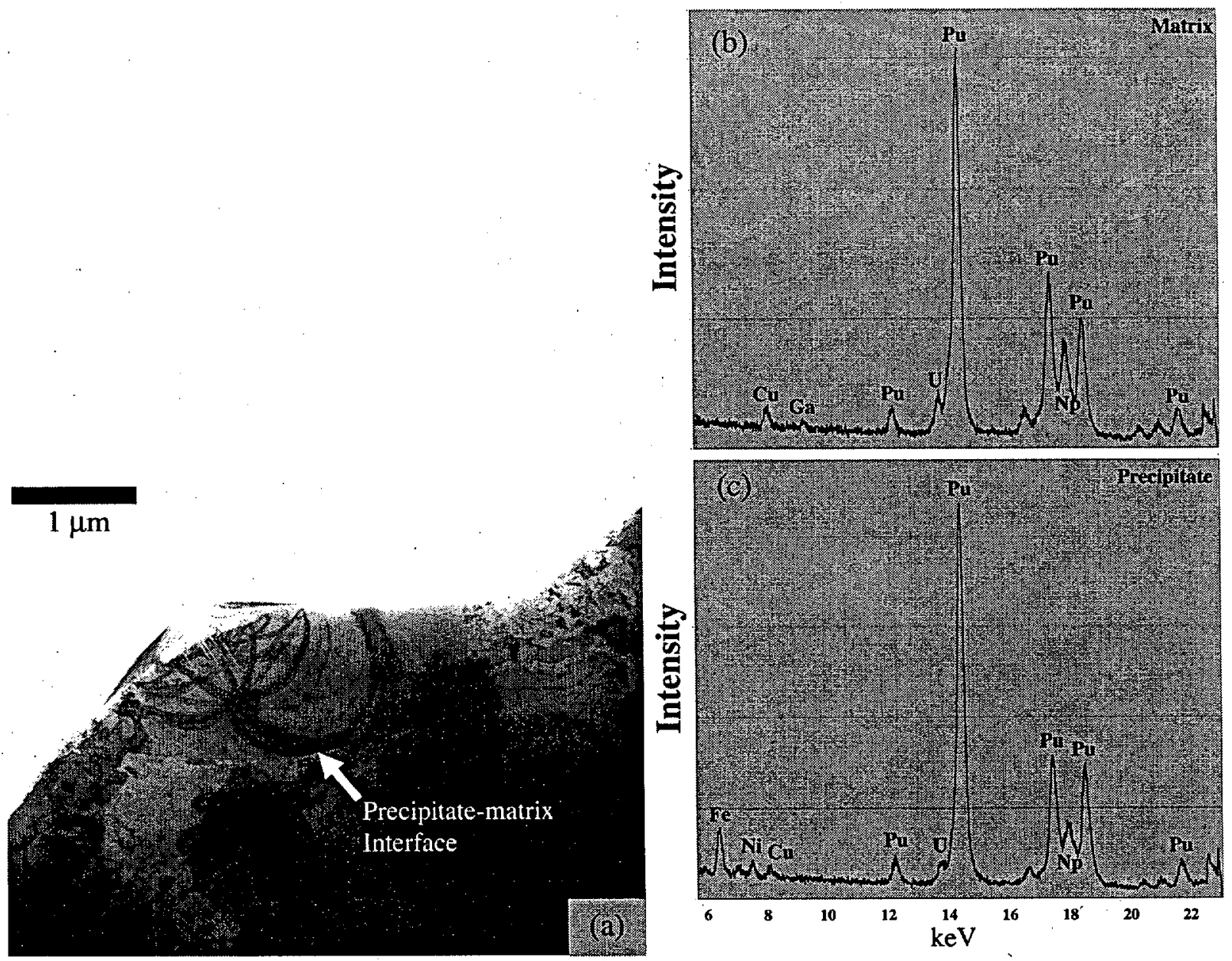

Figure 2. (a) A bright-field TEM image of one of the $\zeta \mathrm{Pu}_{6} \mathrm{Fe}$ precipitates contained in a f.c.c. $\mathrm{Pu}$ matrix. The precipitate-matrix interface is marked with an arrow, (b) Two EDXS spectra taken from; (a) one of the $\zeta \mathrm{Pu}_{6} \mathrm{Fe}$ precipitates and (b) the f.c.c. Pu matrix. Notice that an $\mathrm{Fe}$ peak is found in the spectra for $\zeta \mathrm{Pu}_{6} \mathrm{Fe}$, but is absent in the spectra for the $\mathrm{Pu}$ matrix.

Using high energy-electron energy loss spectroscopy (HE-EELS), TEM, and synchrotronradiation-based X-ray absorption spectroscopy (XAS), we are evaluating the bonding of the $5 f$ states of $\mathrm{Pu}$. The advantage of this approach is that the HE-EELS experiments are performed in a TEM and are coupled with imaging and diffraction data, therefore, the measurements are completely phase specific. Figure $3 \mathrm{a}$ is a TEM image of an $\alpha^{\prime}$ particle imbedded in a $\delta$-matrix. The microstructure has been produced by cooling the Pu-Ga alloy to $150 \mathrm{~K}$ for 10 hours. Figure 
$3 \mathrm{~d}$ is an electron energy loss spectrum taken from an $\alpha$ particle embedded in $\delta$-matrix. Implications of these results to our understanding of bonding will be discussed.
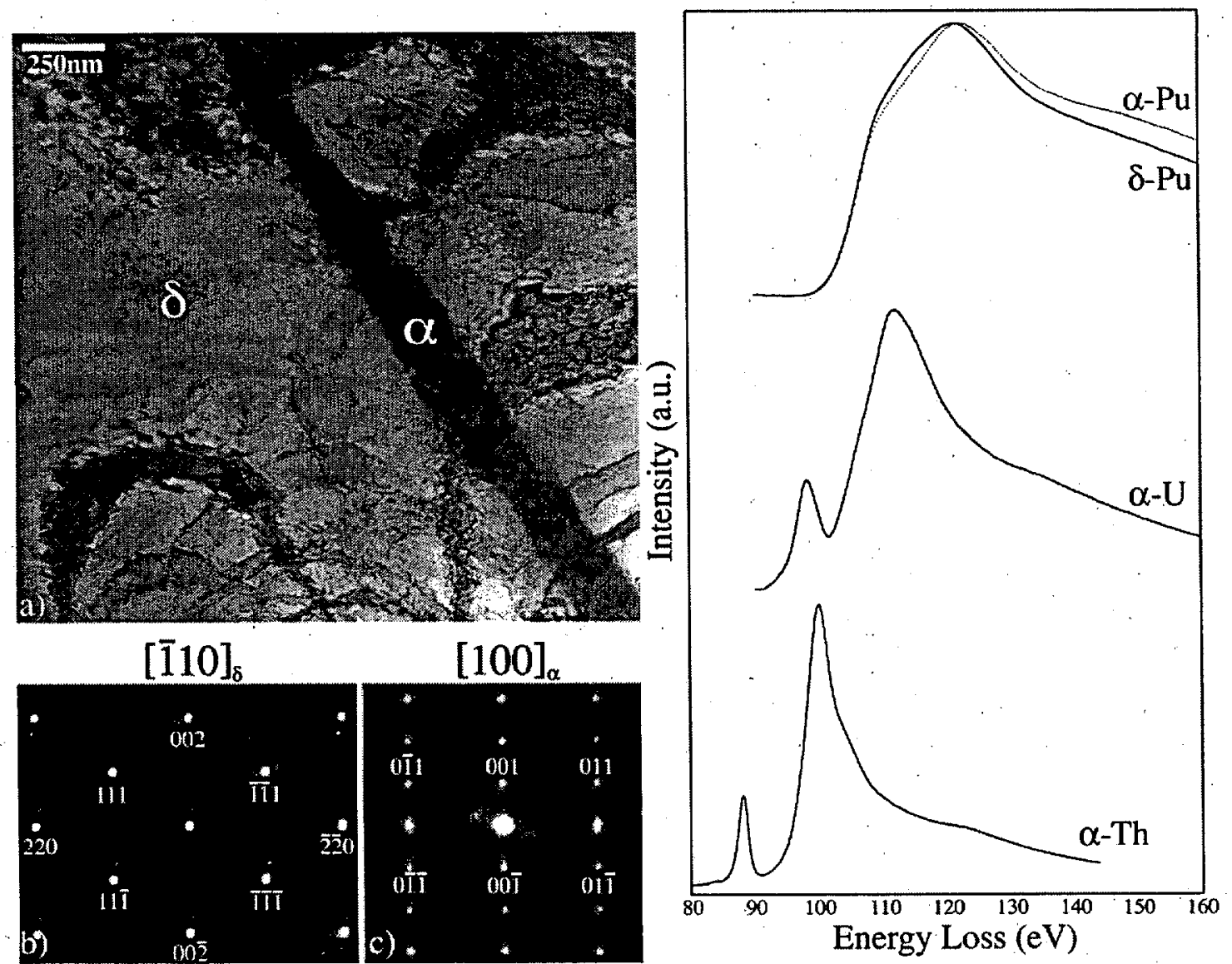

Figure 3. (a) A bright-field TEM image acquired near a $[\overline{110}]_{\delta} \|[100]_{\alpha}$ zone axis showing an $\alpha$ plate in a $\delta$ matrix. (b) A [110] diffraction pattern from $\delta$ and (c) a [100] diffraction pattern from $\alpha$, each with a number of reflections indexed, (d) the $\mathrm{O}_{4,5}(5 \mathrm{~d} \rightarrow 5 \mathrm{f})$ absorption edges from $\alpha$-Th, $\alpha-U, \alpha-P u$ and $\delta$-Pu acquired by HE-EELS in a TEM. These spectra were collected at an accelerating voltage of $297 \mathrm{keV}$ with an energy resolution of $0.8 \mathrm{eV}$.

\section{References}

1. Howell, R.H., Sterne, P.A., Hartley, J., Cawan, T.E., Applied Surface Science 149 (1999) 103-105.

2. Hecker, S.S. and Timofeeva, L.F., Los Alamos Science 26 (2000) 244. 
This work was performed under the auspices of the United States Department of Energy by the University of California, Lawrence Livermore National Laboratory under contract No. W-7405-Eng-48. 